\title{
Peripheral Ossifying Fibroma: A Review and Case Report
}

\author{
Adel Bouguezzi ${ }^{1,2}$, Chaima Khalifa ${ }^{1,2}$, Sameh Sioud ${ }^{1,2}$, Hajer Hentati ${ }^{1,2}$, Jamil Selmi $^{1,2}$ \\ ${ }^{1}$ University of Monastir, Faculty of Dental Medicine, Oral Health and Orofacial Rehabilitation Laboratory Research, \\ Monastir, Tunisia, ${ }^{2}$ Department of Medicine and Oral Surgery, Dental Clinic of Monastir, Monastir, Tunisia
}

\begin{abstract}
The peripheral ossifying fibroma appears as a solitary nodule, frequently occurring in the anterior maxilla. It begins in the cells of the periodontal ligament, and it is more common in children and young adults. Recent lesions are asymptomatic and patients can ignore their presence. However, in the absence of any treatment, they slowly increase in volume. In this paper, we describe a case report of a 40-year-old female patient reported with growth on gingiva in the upper left maxillary region of 1 year ago. The definitive diagnosis is established by histological analyze, which reveals the existence of highly cellular connective tissue with focal calcifications. Surgery is the treatment of choice, though the recurrence rate can reach $20 \%$.
\end{abstract}

Key words: Fibroma, ossifying, peripheral

\section{INTRODUCTION}

The ossifying and cementing fibromas were grouped under one name: Cemento-ossifying fibroma in 1992 by the WHO. It is a benign tumor of non-odontogenic origin characterized by slow and progressive evolution, affecting the maxillae and mainly the mandible in the premolor and molar area. It consists of fibrous tissue containing mineralized tissue resembling bone and/or cementum. ${ }^{[1]}$

We will discuss this lesion to highlight the importance of an early diagnosis so that the surgical treatment is the least mutilating possible.

\section{OBSERVATION}

A 40-year-old female patient reported to the department of medicine and oral surgery with the chief complaint of

\begin{tabular}{|c|c|}
\hline \multicolumn{2}{|c|}{ Access this article online } \\
\hline Publisher & \multirow[b]{2}{*}{$\begin{array}{l}\text { Website: } \\
\text { www.ijdms.in }\end{array}$} \\
\hline & \\
\hline & DOI: 10.30954/IJDMS.1.2020.10 \\
\hline
\end{tabular}

inability to eat due to a growth in maxillary premolars region for 1 year. The lesion had started as a small growth, which had gradually increased to the present size. The patient gave no history of pain and bleeding from the overgrowth. The medical and dental history was non-contributory. The intraoral status revealed a sessile swelling, painless on palpation, consistent firm, and homogeneous, measuring about $1.5 \times 2 \mathrm{~cm}$, located at maxillary premolars region, associated with decayed 24 and 25 [Figure 1]. The growth was firm in consistency and non-tender on palpation with mild bleeding on probing. The patient had very poor oral hygiene.

On radiographic examination, periapical radiograph (intraoral periapical) showed the presence of soft-tissue shadow, interspersed with radiopaque areas suggestive of calcification [Figure 2]. Various etiologies were evocated: Periapical bone dysplasia, ossifying fibroma, or dysplasia fibrous and a provisional diagnosis of peripheral ossifying fibroma (POF) was made for the gingival growth.

The lesion was surgically excised associated with the extraction of 24 and 25; the excised tissue was oval, pale white, and firm inconsistency. Specimen was sent for histopathological examination. The patient was recalled after 1 week for review.

The anatomopathological examination showed a benign tumor lesion of fibro-osseous nature; bone structures of

\footnotetext{
Address for Correspondence:

Adel Bouguezzi, The University of Monastir, Faculty of Dental Medicine, 5019, Monastir, Tunisia. E-mail: dr-adel@live.fr

Submission: 11 May 2020; Revision: 25 May 2020; Acceptance: 29 May 2020
} 


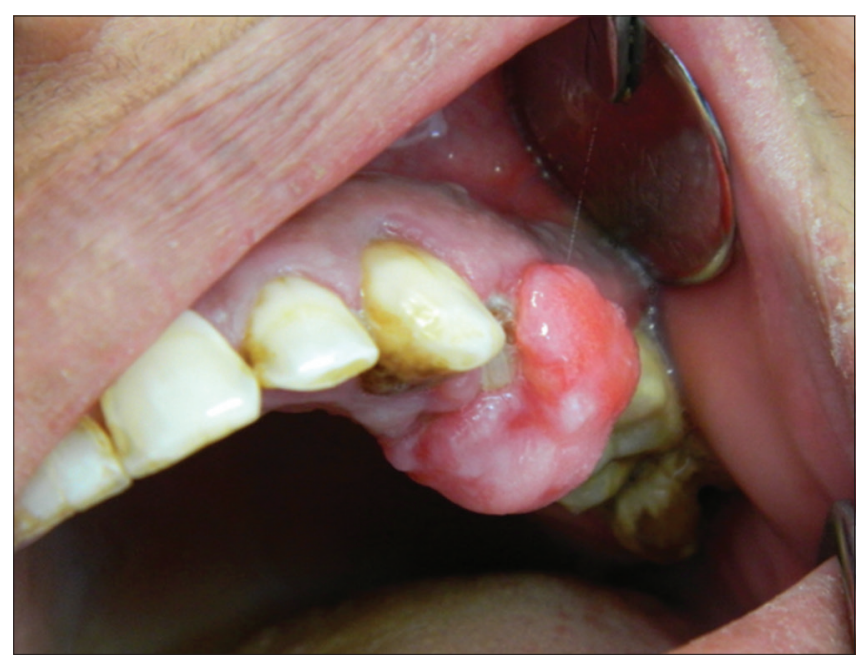

Figure 1: Pedunculated growth on gingiva between premolars

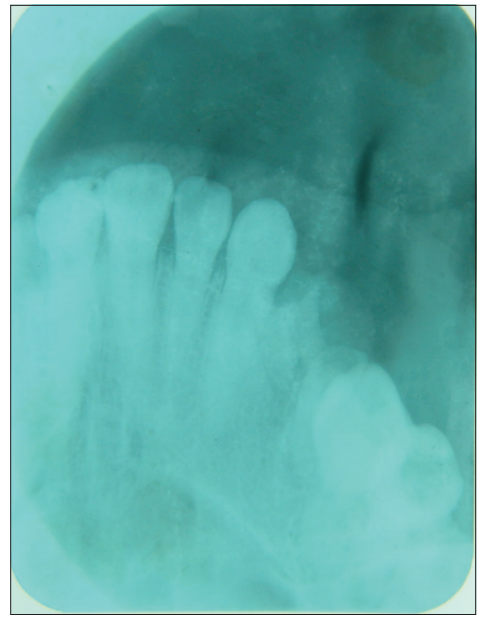

Figure 2: Intraoral periapical radiograph

variable size were observed within a fairly large, spindleshaped, cellular contingent lacking in atypical character. Based on history, clinical presentation, and radiological and histopathological analyze, the final diagnosis of POF was retained.

The patient was seen 1 week follow-up [Figure 3], no scar tissue, and no post-operative pain was observed. Healing was satisfactory. The area of excision was not tender on palpation. The patient was followed up for 1 year, and no recurrence was seen.

\section{DISCUSSION}

Gingival lesions often produced by irritating agents. The diagnosis is usually established based on the clinical findings, with few clinical differences noted among the different disorders included under this term; these disorders include POF, peripheral fibroma, peripheral giant cell granuloma, and pyogenic granuloma. ${ }^{[2]}$ The latter condition could represent

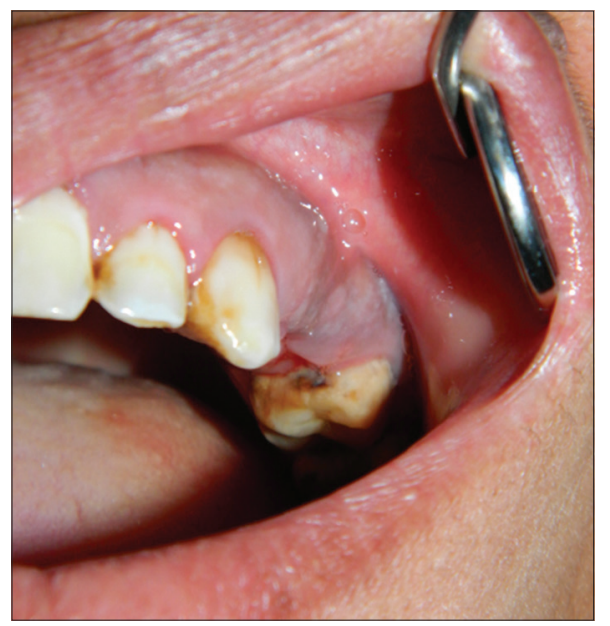

Figure 3: Follow-up after 7 days

an early, immature form of POF. ${ }^{[1,2]}$ A study of 2439 cases of epulis recorded the following prevalence: Peripheral fibromas $61.05 \%$, pyogenic granulomas $19.76 \%$, POF $17.67 \%$, and peripheral giant cell granulomas $1.52 \%{ }^{[7]} \mathrm{POF}$ is firmer and less friable than the rest of the lesions and typically shows a longer course. This explains the calcification and ossification secondary to fibroblast maturation to collagen tissue. ${ }^{[2]}$

Gracia de Marcos et al. ${ }^{[3]}$ stated that the etiology and pathogenesis of POF were not clear. Some authors suggested that this tumor seems to originate from a reaction process which arises from the cells of the periodontal ligament following a traumatic or local irritation such as dental plaque, poor quality dentition, occlusal overload, certain bacterial factors, or by restorations of poor quality promoting the accumulation of dental plaque. ${ }^{[4]}$ In response to these irritants, the pluripotent cells of the periodontal ligament have the power to transform into osteoblasts, cementoblasts, or fibroblasts and therefore to produce a single inflammatory entity, the POF. ${ }^{[5,6]}$

The POF is manifested by a gingival slow-growing mass, well limited, most often measuring a size less than $2 \mathrm{~cm}$ in diameter. However, it should be noted that the lesion can in rare cases measure up to $9 \mathrm{~cm}$ in diameter.

This single nodular mass may be either sessile or pedunculated. The surface color may be identical to the gum or slightly reddish and ulcerated if a traumatic factor or a local irritant exists. On palpation, the color of the swelling does not turn white. The consistency is rather soft but can vary depending on the amount of calcified material, bone destruction has also been reported Verma et al. ${ }^{[7]}$

The radiographic appearances vary considerably from one case to another and depend on the stage of maturity of the lesion and the degree of mineralization. In the early stages, the FO may appear as a radio - clear, unilocular, or multilocular image, and when the lesion matures, it turns 
into a radiopaque lesion with mixed density. The lesion is relatively well limited with the presence of peripheral osteocondensation. The lamina dura of the tooth involved is generally absent and the roots of adjacent teeth can be resorbed in some cases. ${ }^{[8]}$

The internal structure can be a mixture of radiolucent and radiopaque fabric. Expansion of the tumor can sometimes cause tooth displacement or damage to the lower alveolar nerve.

The histological analyzes carried out on our piece of excision were identical and completely compatible with an ossifying fibroma. The chorion was mainly occupied by fibroblasts and collagen elements, among which were mineralized deposits, the bone or cement nature was difficult to specify. The classification of ossifying, cementing, or cemento-ossifying is sometimes imprecise. Some authors place them in the group of tumors and pseudotumors benign non-odontogenic maxilla while the WHO classifies them since 2005 among odontogenic tumors. ${ }^{[9,10]}$

The treatment of ossifying fibroma is based on excision of the lesion, with curettage of the resection cavity. The structures included in the lesion must also be excised. In case of aggressive growth or extensive erosion of surrounding structures, a block resection should be considered as a definitive measure. ${ }^{[1]]}$

Thorough root scaling of adjacent teeth and removal of other sources of irritation should be accomplished. Tooth extraction is seldom necessary. ${ }^{[7,12,13]}$ It is important that the diagnosis is confirmed by a histopathological analysis and that this is preferably carried out by histologists who are experts in oral pathology. ${ }^{[14]}$

\section{CONCLUSION}

A case of the POF is presented here, which appeared clinically as other common gingival lesions such as peripheral fibroma, peripheral giant cell granuloma, and pyogenic granuloma, only histopathological evaluation can give us the definitive diagnosis.

\section{REFERENCES}

1. Kumar SK, Ram S, Jorgensen MG, Shuler CF, Sedghizadeh PP. Multicentric peripheral ossifying fibroma. J Oral Sci 2006;48:239-43.

2. Moon WJ, Choi SY, Chung EC, Kwon KH, Chae SW. Peripheral ossifying fibroma in the oral cavity: CT and MR findings. Dentomaxillofac Radiol 2007;36:180-2.

3. García de Marcos JA, García de Marcos MJ, Rodríguez SA, Rodrigo JC, Poblet E. Peripheral ossifying fibroma: A clinical and immunohistochemical study of four cases. J Oral Sci 2010;52:95-9.

4. Farquhar T, Maclellan J, Dyment H, Anderson RD. Peripheral ossifying fibroma: A case report. J Can Dent Assoc 2008;74:809-12.

5. Mishra AK, Bhusari P, Kanteshwari K. Peripheral cemento-ossifying fibroma-a case report. Int J Dent Hyg 2011;9:234-7.

6. Delbem AC, Cunha RF, Silva JZ, Soubhiac AM. Peripheral cementoossifying fibroma in child. A follow-up of 4 years. Report of a case. Eur J Dent 2008;2:134-7.

7. Verma E, Chakki AB, Nagaral SC, Ganji KK. Peripheral cementoossifying fibroma: Case series literature review. Case Rep Dent 2013;2013:930870.

8. Kenney JN, Kaugars GE, Abbey LM. Comparison between the peripheral ossifying fibroma and peripheral odontogenic fibroma. J Oral Maxillofac Surg 1989;47:378-82.

9. Skinner RL, Davenport WD Jr., Weir JC, Carr RF. A survey of biopsied oral lesions in pediatric dental patients. Pediatr Dent 1986;8:163-7.

10. Cuisia ZE, Brannon RB. Peripheral ossifying fibroma-a clinical evaluation of 134 pediatric cases. Pediatr Dent 2001;23:245-8.

11. Shah K, Kale AD, Hallikerimath S, Chandra S. Peripheral cementoossifying fibroma: Report of a recurrence case. Contemp Clin Dent 2012;3:S23-5.

12. Neville BW, Damm DD, Allen CM, Bouquot JE. Oral and Maxillofacial Pathology. $2^{\text {nd }}$ ed. Philadelphia: WB Saunders Co.; 2002. p. 451-2.

13. Poon CK, Kwan PC, Chao SY. Giant peripheral ossifying fibroma of the maxilla: Report of a case. J Oral Maxillofac Surg 1995;53:695-8.

14. Iyer V, Sarkar S, Kailasam S. Use of the ER, CR; YSGG laser in the treatment of peripheral ossifying fibroma. Int J Laser Dent 2012;2:51-5.

How to cite this article: Bouguezzi A, Khalifa C, Sioud S, Hentati H, Selmi J. Peripheral Ossifying Fibroma: A Review and Case Report. Int J Dent Med Spec 2020;7(1):43-45.

Source of Support: None; Conflicts of Interest: None 